DOI Number: 10.29064/ijma.380252

\title{
ÖRGÜT YAZINININ KURAMSAL İNCELEMESİ VE METAFORİK BİR TASARIM OLARAK MUTLU ÖRGÜT
}

\author{
THEORETICAL REVIEW OF THE ORGANIZATION LITERATURE AND AS A \\ METAPHORICAL DESIGN HAPPY ORGANIZATION
}

Mustafa FIDAN ${ }^{1}$

\section{ÖZET}

Birey ile dünyanın kesiştiği yerde kendini bulan mutluluk, bireysel gereksinimler ile çevredekilerin dengede olduğu kalıcı bir durum olarak tanımlanmaktadır. Benzer şekilde örgütler de birey ve dünyanın kesiştiği her alanda ortaya çıkmaktadır. Örgütler o kadar hayatın içindedir ki, örgütü anlama çabası dünyayı anlama çabasıyla eşdeğer görülmektedir. Mutluluk da bir o kadar hayatın içinde ve anlaşılma çabası bağlamında örgüt kavramından arda kalır değildir. Dolayısıyla mutluluk ve örgüt kavramlarının bireylerin hayatlarında oldukça önemli bir yeri olduğu söylenebilir. Öte yandan, mutluluk algılama olarak ne kadar pozitiflik taşıyorsa, örgüt de bir o kadar negatiflik taşımaktadır. Mutluluk ve örgüt kavramlarını kullanarak, mutlu örgüt metaforunun tartışıldığı bu çalışma zitların uyumu olarak değerlendirilebilir. Bu çalışma, toplum yaşamının bir gerçeği olan örgütleri mutluluk temelinde yeniden ele alma ve mutlu örgüt tasarımını tartışma amacındadır. Metaforik temelde kurgulanan çalışmada, kuramsal olarak mutluluk ve örgüt yazınında destekler araştırılmıştır. Ayrıntılı bir literatür taraması ile sistematik bir yapı içerisinde mutlu örgüt tasarımı tartışılmıştır. Mutlu örgüt, yönetenlerin, çalışanların ve müşterilerin hep birlikte mutlu oldukları ve aynı zamanda örgütsel hedeflerin başarıldığı bir örgüt tasarımıdır. Bu tasarım, örgütte yer alan her bireyin mutluluğu temeline dayanır. Yöneten, çalışan ve müşteri olmak üzere üçe ayrılan örgüt bireyleri, hiçbiri dışarda kalmayacak şekilde bir mutluluk sarmalında bütünleşmektedir. Mutlu örgüt, mutluluk ve örgüt yazınıyla tam uyuşan, daha yaşanabilir örgütler hedefli bir tasarımdır. Geleceğin örgütleri için mutlu örgüt metaforu önemli açıklayıcılar sunmaktadır.

Anahtar Kelimeler: Mutluluk, Örgüt, Mutlu Örgüt, Metafor

\begin{abstract}
Happiness takes place in the meeting between person and World. Likewise organizations are also emerges in all areas of the intersection of individual and world. Organizations are all part of the daily life that, to understand organizations is to understand our world. Thus, we said to be the concept of happiness and organization a very important place in lives of individuals. This study aims to reconsider the organizations which are the facts of social life on the basis of happiness and discuss the design of happy organization. Being designed on a metaphorical
\end{abstract}

\footnotetext{
${ }^{1}$ Doktora Öğrencisi, Hacettepe Üniversitesi, Eğitim Bilimleri Bölümü, Eğitim Yönetimi Bilim Dal1,gfidanmustafa@gmail.com
} 
basis, this study examines theoretical literature on happiness and organization. Happy Organization design is discussed in a systematic structure with a detailed literature review. Happy organization is a organizational design in that managers, employees and customers are always happy and they also achieve organizational goals. This design is based on the happiness of every individual in the organization. Being classified into three categories as manager, employee and client, all of these people are integrated into each other in a happiness spiral without excluding any one. Happy organization is an organizational design aiming to create more livable organizations tuning with the literature on happiness and organization. Happy organization metaphor offers significant explanatories for the organizations of the future.

Keywords: Happiness, Organization, Happy Organization, Metaphor

\section{Giriş}

Örgüt yaşamını anlama bir bilim ve sanat olarak her dönemde insanların dikkatini çekmiştir. Bu amaçla farklı dönemlerde birçok örgüt kuramı üretilmiştir. Bütün bu kuramlar incelendiğinde, temellerinde örtük imgeler ve metaforların olduğu görülecektir (Morgan, 1998). Başka bir ifade ile örgüt kuramlarının doğasında metaforlar vardır. Türk Dil Kurumu (TDK) sözlüğünde mecaz karşılığ1 verilen kavram metafor olarak da kullanılmaktadır. Metafor (mecaz) "bir kelimeyi veya kavramı kabul edilenin dişında başka anlamlara gelecek biçimde kullanma" olarak tanımlanmaktadır (TDK, 2016). Benzer bir tanımda ise metafor, bir alandan bilinen bir bilgiyi yeni ve çoğunlukla bilinmeyen bir alana aktarımı olarak ele alınmıştır (Tsoukas, 1991). Metafor, karmaşık örgüt olaylarının farklı yönlerine odaklanma, anlama ve etkileme için farklı düşünme yollarını teşvik etmektedir (Morgan, 1998; Tsoukas, 1991).

Öte yandan metaforlarla aktarılan bilgi ve deneyim ile yeni olanı ayırt edici bir şekilde görme, anlama ve yönetme gücünün kısmi olduğu söylenebilir. Metaforlar deneyimlerin benzer yönlerini öne çıkarıp güçlü bir kavrayış sunarken farklı yönlerini göz ardı etmektedir. Metaforlar bu kabul üzerine inşa edilir. Her iki alandaki benzer yönleri güçlü bir şekilde öne çıkararak yeni alana ilişkin "bir düşünme ve görme biçimi" geliştirilmektedir (Morgan, 2007, s.14). Örgüt yazınında var olan, makine metaforu, kültür metaforu ve organizma metaforu bu bağlamda üretilmiş metaforlar olarak örgüte ilişkin düşünme ve görme biçimi sunmaktadırlar. İnsanın kavramsal sistemi metaforlara dayalı olduğundan (Lakoff ve Johnson, 1980) örgüte ilişkin metaforlara her geçen gün yenileri eklenmektedir.

Örgüt yazınına yeni bir metafor perspektifinden bakılmak istenen bu araştırmanın beslenme kaynakları mutluluk ve örgüt metaforları yazınıdır. Popper'a (2005, s.25) göre araştırma, deyim yerindeyse, "damdan düşer gibi" başlar. Diğer bir ifade ile bir araştırma başlangıcı için düşecek bir dama gereksinim duyulmaktadır. Mutluluk yaşamın da eğitimin de çok temel bir amacı aynı zamanda yapılan her şeyi ölçüsüne vurabileceğimiz bir mihenk taşı (Noddings, 2006, s.11) olarak bu metaforda özenle seçilmiş ve kullanılmaktadır. Mutluluk merkezli bir anlayışla tasarlanan mutlu örgüt, 
çalışanlar, müşteriler ve yöneticilerin hep birlikte mutlu olduğu bir mutluluk sarmalı olarak tanımlanabilir.

\section{Kuramsal İnceleme}

\subsection{Mutluluk}

Günlük yaşamda sıklıkla kullanılan temel kavramlardan olan mutluluk, akademik olarak da yoğun çalışılan bir kavramdır (Benditt, 1974; Davis, 1981; Diener ve Seligman, 2002; Goldstein, 1980; Griffin, 2007; Haybron, 2001, 2003, 2005, 2007; McMahon, 2005; Noddings, 2003; Nussbaum, 2008; Oishi ve ark., 2013; Thomas, 1968; Veenhoven, 2003, 2005; White, 2006; Wilson, 1968). Griffin (2007) mutluluk çalışmalarını genel olarak inceleyerek, "mutluluk çalışmaları neyi araştırır?" sorusunu yöneltmektedir. Ona göre mutluluk çalışmaları kavramsal olarak öznel anlamlar yüklendiği ve ortak bir anlam bulunmadığı için her şeyi araştırmaktadır. Benditt (1974) "Mutluluk" isimli çalışmasında, kavramı Aristo'ya kadar götürmekte ve birçok yönden ele almaktadır. White (2006) "Mutluluğun Kısa Bir Tarihi" isimli çalışmasında Aristo'nun "insan iyiliği”" (the human good) tanımına yer vermiş ve halen de tanımda çok bir şeyin değişmediğini söylemektedir. Uyl ve Machan (1983), Aristo'nun "eudaimonia" kavramını "iyi giden-mamur insan" (human flourishing) kavramını ile açıklamaktadır. Dolayısıyla genel yazın incelendiğinde mutluluk kavramı tartışmalarının Aristo ile başladığı görülmektedir.

Aristo'dan bugüne sayısız mutluluk tanımı yer almaktadır. Mutluluk, her şeyden önce sıradan insanların iyi bir yaşam yönetiminde kendi günlük ilgilerini karşılamak için kullanılan sosyo-psikolojik (folk psychological) bir kavram olarak tanımlanmaktadır (Haybron, 2003). Benzer şekilde Oishi ve arkadaşları (2013) da mutluluğun kültürel yönüne vurgu yapmışlardır. Başka bir tanımda mutluluk, bir kişinin mevcut genel yaşamını değerlendirirken toplam pozitiflik derecesi olarak tanımlanmıştır. Bir diğer ifade ile, kişinin sürdürmekte olduğu hayatı ne kadar sevdiğiyle ilişkili olarak mutluluk tanımlanmaktadır (Veenhoven, 2005). Başka bir yerde mutluluk, belirli bir zaman dilimi içinde kişinin kendi yaşamıyla tatmin olması şeklinde tanımlanmaktadır (Benditt, 1974, s.8). Bir başka görüşe göre mutluluk, kısa ve kalıcı mutluluk olarak ikiye ayrılmalıdır. Çünkü hemen hemen her insan kısa mutluluk deneyimini bilirken, neredeyse hiç kimse kalıc1 mutluluk halini bilmemektedir (Jacobsen, 2007). Kısa olan mutluluk olağan, sıradan olarak ifade edilirken gerçek mutluluğun kalıcı olan olduğu belirtilmektedir. Olağan mutluluk, bir kişinin gerekli tüm ihtiyaçlarının yerine getirilmiş olduğu hissini taşımasını içeren kısa bir hali anlatır. Gerçek mutluluk ise bireyin kendi bireysel istek, amaç ve gereksinimleri ile çevredekilerin dengede olduğu kalıcı bir durum anlaşılmaktadır (Jacobsen, 2007). Bu son tanıma göre mutluluk, birey ile dünyanın kesiştiği yerde yer alır (Jacobsen, 2007).

Görüldüğü gibi mutlulukla ilgili birçok farklı tanım bulunmaktadır. Tanımların yanında bu alanda oyunun kurallarını bilmek için alanın teorilerine de bakılması gereklidir. Günlük yaşamda kullanılan merkezi kavramlardan biri olarak mutluluk (Haybron, 2003), kuşkusuz birçok kurama sahip olacaktır. Uyl ve Machan (1983) mutluluk üzerine 
çok şeyin söylenmiş olduğunu ifade ederken bunları sınıflandırmada araştırmacının görüşünün oldukça belirleyici olduğunu belirtmektedir. Başka bir ifade ile mutluluk araştırmaları çok geniş bir alanda ve sübjektif niteliktedir. "Bir mutluluk teorisi" isimli çalışmasında Davis (1981), inanç, arzu, düşünce ve mizaç olmak üzere dört değişken tarafından etkilenen bir kavram olarak mutluluk teorisi kurgulamıştır. Mutluluk yazını genel olarak incelendiğinde ise hedonizim (hazc1lık), yaşama ilişkin toplam tutumlar (life satisfaction) ve duygusal durum teorisi (affective state theories) olmak üzere üç temel anlayış öne çıkmaktadır (Haybron, 2003).

Mutluluk teorilerinin ilki olarak hedonizm, bireylerde yaşamın toplamında hoşnut olacağ 1 durumların hoşnut olmayacağı durumlardan görece çok olmasını mutluluk için gerekli görmektedir (Haybron, 2003). Başka bir tanımda hedonizm, keyif, haz ve zevkin önemli bir rol oynadığı yaşam biçimi olarak tanımlanmaktadır (Veenhoven, 2003). Hedonik görüşe göre hoşnutsuz durumların bireyin mutluluğunu azaltacağ1 düşünülmektedir. İkinci teoride, bireylerin kendi hayatlarına ilişkin tutumları (life satisfaction) mutluluk olarak değerlendirilmektedir. Burada mutluluk, belirli bir zaman dilimi içerisinde bireyin bütün olarak hayatına ilişkin olumlu tutuma sahip olmasında aranmaktadır (Haybron, 2003). Bir başka kaynakta hayata ilişkin tutumlar olarak mutluluk, belirli bir zaman dilimi içinde kişinin yaşamıyla tatmin olması şeklinde tanımlanmaktadır (Benditt, 1974, s.8). Üçüncü olarak ise duygusal durum teorisi yer almaktadır. $\mathrm{Bu}$ görüş hedonizme çok yakın olmakla birlikte, deneysel çalışmalarda sıklıkla kullanılmaktadır. Bu temel görüşlerin yanında birçok melez görüş de mutluluk yazınında yer almaktadır. Bunların en bilinen örneklerinden biri olarak "öznel iyi oluş" (SWB) verilebilir (Haybron, 2003). Diener ve Diener (1996) deneysel çalışmasında benzer bir bakışla, mutluluğu öznel iyi oluş üzerinden açıklamaktadır.

\section{2. Örgüt}

Genel olarak örgüt, bir grup insanın üzerinde anlaşılmış ortak amaçları gerçekleştirmek için geliştirdikleri bilinçli bir düzenleme, sosyal bir ünite ve eşgüdüm sistemi olarak tanımlanmaktadır (Barnard, 1938, s.73; Selznick, 1948; Robbins ve Coulter, 2012, s.6; Langton ve Robbins, 2004, s.5). Örgüt kavramı tanımlanırken, bir hareket veya sürecin örgütlenmesi ve kendini oluşturan bileşenlerin çeşitli fonksiyonları ile bütüne katkıda bulunması birlikte ele alınmaktadır (Leonardi ve Barley, 2011). Dolayısıyla bir örgüt olarak okulların (Bell 1980), ortak amaç çerçevesinde bilinçli bir örgütlenme olduğu söylenebilir.

Örnekte verilen okul birçok örgüt içerisinde sadece bir tanesidir. Bireyler bir örgüt olan hastanede doğmakta, küçük yaşlardan itibaren uzun bir eğitim süreci için örgütler olan okullara başvurmakta ve yaşamın her alanında örgütlerle iç içe yaşayıp yine bir örgütle yaşamını sonlandırmaktadır (Illich, 2012, s.7). Kısaca yaşamın hiçbir anı örgütlerden soyutlanamamaktadır. Baum ve Rovley (2002) örgütleri anlamak dünyayı almaktır ifadeleriyle bu gerçeğe vurgu yapmaktadır. Gerçek bu olduğuna göre yapılması gereken örgütlerin çok iyi anlaşılması ve iyi yönetilmesi olmalıdır. 
Bu kapsamda birçok çalışma olmakla birlikte her geçen gün yeni örgüt metaforları üretilmektedir (Morgan, 1998). Örgüte ilişkin üretilen metaforlarla örgütün doğası daha iyi anlaşılmakta ve daha işlevsel yönetilebilmektedir. Doğasında bu metaforların bulunduğu örgüte ilişkin yaklaşımlar örgüt tanımlarını da etkilemektedir. Örgüte ilişkin nasıl bir tanımlama yatığımız ise örgütsel bağlamda düşünce üretiminin çerçevesini belirlemektedir (Scott ve Davis, 2007, s.27). Dolayısıyla örgüt yazınında birçok tanım ve yaklaşım yer almaktadır.

Scott ve Davis (2007) örgüte ilişkin temel yaklaşımları rasyonel, doğal ve açık olmak üzere üç başlık altında ifade etmişlerdir. Rasyonel sistemler olarak örgüt, görece belirli hedefleri gerçekleştirmeye odaklanmış ve yüksek derecede formalize edilmiş sosyal yapılar olarak tanımlanmaktadır. Doğal sistemler olarak örgüt ise, belirli bir ortak çıkarı gözeterek ve önemli bir kaynak olarak örgütün devamlılığının değerini anlayan birliktelikler şeklinde tanımlanmaktadır. Ve son olarak açık sistemler olarak örgüt, daha geniş materyal-kaynak ve kurumsal çevrelerle iç içe geçmiş katılımcıların değişen koalisyonları arasında ilişki kuran birbirine bağımlı akış ve faaliyet kümesi olarak tanımlanmaktadır. Birbiri ile çelişen, örtüşen ve birbirini tamamlayan yönleriyle bu tanımların her biri çok karmaşık örgütü daha iyi anlama çabasının ürünüdürler (Scott ve Davis, 2007, s.32).

$\mathrm{Bu}$ temel örgüt yaklaşımlarının yanında birçok çağdaş örgüt yaklaşımı da bulunmaktadır. Bunlara ilişkin görme kolaylığı sağlamak amacıyla Baum ve Rovley (2002) tarafından on farklı başlık altında çağdaş örgüt yaklaşımları açıklanmıştır. Şekil 1 çağdaş örgüt yaklaşımlarını ve bunlar arası ilişkiyi bir bütün halinde göstermektedir. 


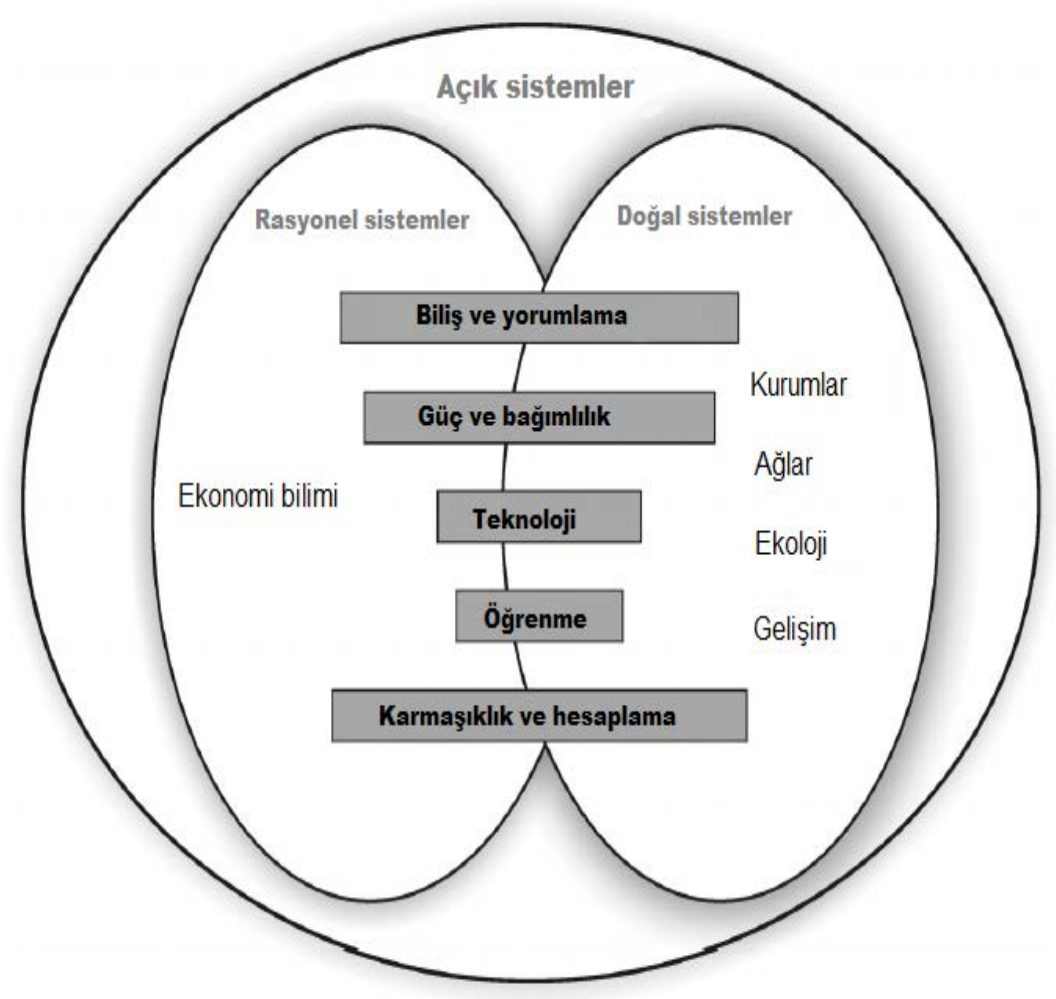

Şekil 1. Çağdaş örgüt yaklaşımları görselleştirmesi: Rasyonel, doğal ve açık sistemler

Şekil 1'de ifade edilen yaklaşımlar birer teori değildirler. Fakat birkaç teorinin bileşimi olarak düşünülebilirler. Örneğin örgüte ilişkin ekonomik yaklaşım, endüstriyel örgüt, kaynak tabanlı örgüt, işlem maliyeti ve oyun teorisini içine alacak şekilde tasarlanmıştır. $\mathrm{Bu}$ perspektifler kendi içinde bütünleştirilen teorilerle oluşturulmuştur. Aynı zamanda her bir perspektif de birbirini destekler şekilde bütüne yerleştirilmiştir (Baum ve Rovley, 2002) . Çağdaş araştırma yaklaşımları birbiri ile mücadele etmeye değil birbirine destek olmaya eğilimlidirler. Bu nedenle bu görsel tasarlanırken kendi içinde ve bütün olarak karşılıklı ilişki ve işbirliği temel alınmıştır. Rasyonel, doğal ve açık sistem yaklaşımını ile diğer yaklaşımlar bu tasarımın içerisine işbirliği içinde yerleştirilmiştir. Dolayısıyla çağdaş örgüt yaklaşımları daha bütüncül ele alınmıştır.

\section{Metaforik Bir Tasarım Olarak Mutlu örgüt}

Bütüncül bir perspektif içinde anlatılan örgüt yaklaşımları gün geçtikçe yeni metaforlar ve teorilerle gelişmektedir. Yaklaşımlarla uyumlu kuramlar ve kuramlarla uyumlu gelişen metaforlar bütünün mikro düzeyde açıklanması bağlamında önemlidir. Scott (1997) "Modernitenin Makine Metaforu" isimli çalışmasıyla önemli bir açıklayıcı sunmaktadır. Şöyle ki, metaforlar sadece kuramı ve yaklaşımı değil, paradigmayı da açıklama potansiyeline sahiptir. Makine metaforu, bilindiği gibi rasyonel örgüt yaklaşımı ve klasik yönetim kuramlarının yanında modern paradigmayı da açıklamada önemli bir aktördür. Yukarıda belirtildiği gibi çağdaş araştırma yaklaşımı kendi içinde ve bütüncül anlamda bir karşılıklı ilişki içindedirler. 
Mutlu örgüt kavramı da metafor olarak çeşitli kuram, yaklaşım ve paradigmada ile karşılıklı ilişki içerisindedir. Mutlu örgütün, paradigma olarak post modern bir anlayışta olduğu söylenebilir. Modern paradigmanın akıl merkezli, nesnel ve genelleyici temel düşüncesi yerine, duyguları da dişarda bırakmayan, öznele alan açan ve çoğulcu bir anlayış sunan postmodernizm (Şişman, 1996) mutlu örgüte daha yakındır. Her örgütün kendi bağlamında bir gerçeklik olduğu ve ona göre değerlendirilmesi gerektiği ifade edilmektedir. Bu bağlamda yapılan tartışmalar postmodern örgütü ortaya çıkarmıştır. Postmodern örgüt tartışmaları ile eşzamanlı olarak örgüt yazınında, kültür, iklim, imaj ve kimlik konuları tartışılmaya başlanmıştır. Benzer şekilde örgüt yazınında postmodern paradigma ile birlikte yönetim kavramı yerini liderliğe bırakma eğilimindedir (Şişman, 1996, s.460).

Liderlik, mutlu örgütler için de anahtar kavramlardan biridir. Balcı (1988;2014), etkili okul çalışmalarında, liderliğin etkili okullar için vazgeçilmez olduğunu belirtmektedir. Etkililiğin (Barnard, 1938) önemli bir bileşen olduğu mutlu örgütlerde liderlik önemlidir. Kendi kendilerine liderlik etmeleri amacıyla bireylere liderlik etme olarak tanımlanan süper liderlik (Manz ve Sims, 1991) mutlu örgütler için önemli bir açıklayıcıdır. Ayrıca dönüşümcü liderlikteki bireysel ilgi boyutu (Burns, 1978; Bass, 1990); öz liderlikte örgütsel kararlara katılım (Manz ve Sims, 1991); kuantum liderlikte lider takipçi etkileşimi (Erçetin, 1999); sosyal adalet liderliğindeki kapsayıcılık (Özdemir ve Kütküt, 2014) ve dağıtımcı liderlikteki işbirliği (Heck ve Hallinger, 2009; Özdemir, 2012) mutlu örgütler hedefinde önemlidir.

İşbirliği mutlu örgüt tasarımı içeren bu çalışmanın temel kavramlarındandır. Bu çalışmanın ana taşıyıcılarından bir tanesi hatta en önemlisi Barnard'ın (1938) işbirliği kuramıdır. Yönetim alanında bir efsane olan "The Function of Executive" kaynağındaki örgüt tanımı ve çeşitli kavramlar (denge, etkililik, etkinlik, kabul alanı vb.) mutlu örgüt için temel oluşturmaktadır. Burada Barnard, örgütün ortak amaçları gerçekleştirme derecesi (etkililik) ile çalışanların bireysel ihtiyaçlarının karşılanması derecesi (etkinlik) arasında bir denge üzerine örgüt kuramını (işbirliği) inşa etmiştir. Weber gibi yapıya, Taylor gibi yönetime, Elton Mayo ve arkadaşları gibi insan ilişkilerine odaklanma yerine Barnard'da örgütün işlevine odaklanılmış ve işbirliği kuramı oluşturulmuştur (Pugh ve Hickson, 2016). Benzer bir anlayışla mutlu örgüt kavramı, örgütü oluşturan bileşenleri işlevsel bir anlayışla kurgulamaktadır.

Mutlu örgüt ayrıca, doğal rasyonel açık sistemler içinde değerlendirilebilir. Şekil 1'de yer alan açık, rasyonel ve doğal sistemlerin kesişimi bağlamı mutlu örgüt için daha uygundur. Örgüte bilişsel kavramları uygulayan biliş ve yorumlama yaklaşımı temel üç yaklaşımı da dışlamamaktadır (Baum ve Rovley, 2002). Bu bağlamda mutlu örgüt tasarımı da postmodern bir örgütsel metafor olarak kendinden önceki temel yaklaşımları bütüncül bir yaklaşımla içinde barındırmaktadır. Bu sayede temel yaklaşımların birbirini tamamlayan yönleri mutlu örgüt tasarımını daha da güçlendirerek, örgütü daha iyi anlama çabasını destekleyecektir (Scott ve Davis, 2007, s.32). Örgütün rasyonel tarafları vardır ve bunlar göz önünde bulundurulmalıdır. Aynı zamanda örgüte ilişkin 
formal yapılar yanında informal oluşum ve süreçler de olabilecektir. Mutlu örgüt örgütün doğal yanını da kabul etmektedir. Buna ek olarak açık sistemler olarak mutlu örgüt tasarlanmıştır. Meyer'in "açık kapalı sistem tartışması açık sistemler lehine kapanmıştır” ifadesi (Hoy ve Miskel, 2012, s.8), mutlu örgütler için de geçerlidir.

Örgüt yazınında mutluluk konulu birçok çalışma görülmektedir. Bunlar çalışanların mutluluğu, müşterilerin mutluluğu ve yöneticilerin mutluluğu olmak üzere üç başlık altında toplanabilir. Çalışanların mutluluğu denildiğinde Hawthorne çalışmalarından başlanabilir. $\mathrm{Bu}$ çalışmalarda mutlu çalışanların örgütsel verimliliği artırdığına (Zelenski, Murphy ve Jenkins, 2008; Wright ve Staw, 1999; Staw, 1986; Fogaça ve Junior, 2016) ilişsin ampirik bulgular vardır (Quick ve Quick, 2004). Diğger bir boyut olarak yöneticilerdeki mutluluğu önemle çalışılan konulardandır. Yine bu çalışmalar da örgütsel amaçların başarılmasında yönetici mutluluğunun olumlu katkıları olduğuna ilişkin kanıtlar yer almaktadır (Visser ve ark., 2013; Sullivan ve Masters, 1988; Jin, Seo ve Shapiro, 2016). Mutlu örgütün üçüncü bileşeni olan müşteri mutluluğu zaten herkesçe kabul edilen, bütün örgütler için olmazsa olmaz bir hedeftir. Çünkü müşteri örgütün oluş nedenidir (Eroğlu, 2005; Fornell, 1992). Müşteri, çalışan ve yönetici bileşenleri hep birlikte mutluluğu mutlu örgütü ortaya çıkarmaktadır. Şekil 2 mutlu müşteri, mutlu çalışan ve mutlu yönetici bileşenlerinden oluşan mutlu örgüt sarmalını açıklamaktadır.

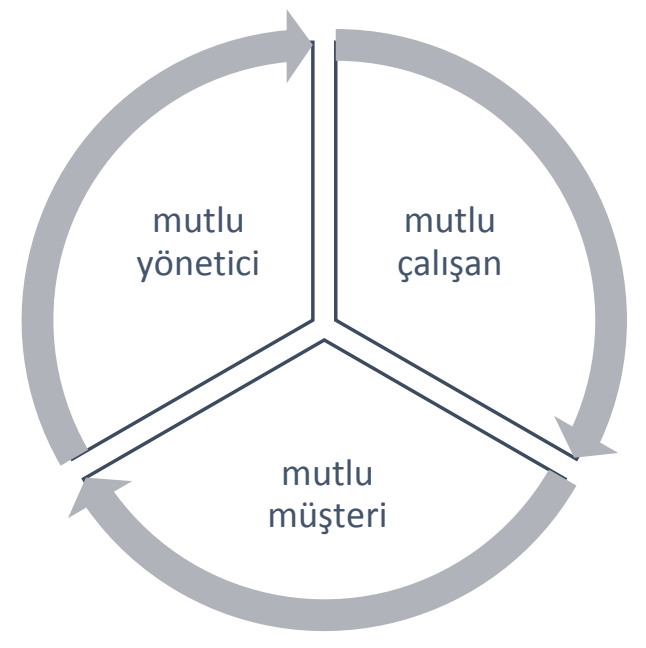

Şekil 2. Mutlu örgüt sarmalı ve mutlu örgütün bileşenleri

Okul örneğinde düşünüldüğünde, öğrenci, öğretmen-diğer personel ve yöneticilerden oluşan üç yönlü bir mutluluk sarmalı öngörülebilir. Bu şekilde öngörülen mutluluk sarmalı mutlu okul olarak isimlendirilebilir. Mutlu okul, öğrenci, öğretmen-diğer personel ve yönetici olmak üzere üç bileşenin hep birlikte mutlu olması ile etkin aynı zamanda örgütsel hedeflerin gerçekleşmesiyle de etkilidir. Buradaki etkinlik ve etkililik kavramları Barnard (1938) tarafından açıklanan anlamda kullanılmaktadır. Mutlu okula benzer şekilde mutlu fakülte somutlaştırması da yapılabilir. Mutlu fakülte, yöneticileri (dekan, dekan yardımcıları, bölüm başkanları, anabilim dalı başkanları), akademik-idari 
personeli ve öğrencileriyle topyekûn bir mutluluk hedeflemektedir. Mutlu örgütteki mutluluk, hem üç ayrı başlıkta kişilerin isteklerini gözetirken hem de örgütün hedeflerinin gözetilmesini gerektirmektedir.

Döş (2013), Mutlu Okul isimli çalışmasında, okulların mutlu mekanlar olması hedefiyle öğrenci görüşlerinde mutlu okulu tanımlamaya çalışmıştır. Çıkış noktası olarak bu çalı̧̧aya benziyor görünse de yöntem olarak dar kapsamlı gözüken çalışmada, okulun mutluluğu öğrenci bileşeni bağlamında incelenmiştir. Mutlu örgüt kavramının üç yönlü bakış açısında ise okulların mutluluğu, öğrenci, öğretmen-diğer personel ve yönetici bileşenlerini kapsama dahil etmektedir. Sadece öğrenci açısından mutlu okul arama Elton Mayo ve arkadaşlarının İnsan İlişkileri kuramını hatıllatmaktadır (Bursalıoğlu, 2012; Pugh ve Hickson, 2016). Bu yönüyle öğrenciye odaklanan çalışmalar her ne kadar kulağa hoş gelse de örgütsel hedeflerden uzaklaşma yönüyle eleştirilme ile karşı karşıya kalacaktır. Barnard'ın (1938) işbirliği kuramında ise iki yönlü bir denge söz konusudur.

Mutlu örgüt, hem birey-örgüt arasında hem de müşteri-çalışan ve yönetici arasında bir denge düşüncesiyle tasarlanmıştır. Bu tasarım, alanyazında önemli bir boşluğa karşıllık üretilmiştir. Örgüt yazını incelendiğinde bu şekilde kapsamlı bir mutluluk çalışması görülememiştir. Sadece müşterilerin, sadece çalışanların ve sadece yöneticilerin mutluluğu üzerine odaklanma bir eksiklik olarak düşünülmektedir. Alanyazında var olan örgüt kuram, yaklaşım ve paradigmalarından ilhamla mutlu örgüt tasarlanmıştır. Bu bağlamda müşteriler, çalışanlar ve yöneticilerin birlikte mutlu olmalarıyla "etkin" aynı zamanda örgütsel amaçların gerçekleştirilmesiyle "etkili" (Barnard, 1938) mutlu örgütler tartışmaya açılmaktadır. Etkinlik başlığı altında sıralanan mutlu yönetici, mutlu çalışan ve mutlu müşteri mutlu örgütün bileşenlerini oluşturmaktadır.

Mutlu Yönetici: Bilimsel bir disiplin olarak 1950'li yıllarda ortaya çıkan yönetim, uygulama olarak insanlığın ilk zamanlarına kadar giden bir geçmişe sahiptir. Yönetim yazını kısa süreli bilimsel yazın geçmişine rağmen dünya çapında hızla yaygınlaşan bir disiplindir (Drucker 2011: 219). Yönetim bilimsel bir faaliyet oluşunun yanında, sosyal bir işlev ve gerçek bir sanat olarak da ifade edilmektedir (Hoy ve Miskel, 2012, s.8; Drucker, 2011, s.219). Genel olarak yönetim, örgüt faaliyetlerinin insanlarla ve insanlar üzerinden verimli bir şekilde tamamlanma süreci olarak tanımlanmaktadır (DeCenzo ve Robbins, 2005, s.35). Örgüt bir yapı, yönetim bu yapıyı işleten bir süreç (Bursalıoğlu, 2010) olarak ifade edilmekte ve bu süreci işleten yöneticileri gerektirmektedir (Drucker, 1999, s.8). Yönetici, örgütsel amaçları gerçekleştirebilmek için diğer insanların çalışmalarını koordine eden ve denetleyen kişidir (Robbins ve Coulter, 2012, s.5).

Örgütsel amaçları gerçekleştirme bağlamında modern zamanların önemli kavramlarından olan yönetici, postmodern paradigmanın etkisiyle yerini lider kavramına bırakmıştır (Şişman, 1996, s.460). Yönetici ve lider tanımları incelendiğinde, liderin yönetici özelliklerine sahip olmakla beraber daha fazlasını da ortaya koyması gereken kişilerdir olduğu söylenebilir. Bir başka ifade ile liderlik, yönetici kavramını kapsayan bir kavramdır denilebilir (Markham ve Markham, 1995). Birçok tanımı 
yapılan liderliğin etkileme, bir grup ve ortak amaç olmak üzere üç bileşeni vardır (Bryman, 1992). Bir grubu ortak amaçlar çerçevesinde etkileyebilme ve harekete geçirme süreci olarak liderlik (Yukl, 2010, s.26), takipçilerin performansları ile ölçülebilir (Kaiser, Hogan ve Craig, 2008). Takipçilerin performansları üzerinde liderin mutluluğu (Jin ve ark., 2016), yüz ifadesi (Sullivan ve Masters, 1988) ve olumlu veya olumsuz duygu yansitması (Visser ve ark., 2013) önemli birer belirleyicidirler. Dolayısıyla mutlu örgüt bağlamında mutlu yönetici önemli bir bileşen olarak ele alınmaktadır.

Mutlu Çalışan: Tüm örgütler, hedefledikleri ortak amacı başarabilmek için amaçlarının doğasına uygun nitelik ve sayıda insan kaynağına gereksinim duyarlar (Özdemir, 2014, s.2). İnsan kaynağı, örgüt amaçlarının başarılması sürecinde sahip olduğu bilgi beceri ve yetenek ile örgüte katkı sağlayan kişiler olarak tanımlanabilir (Çetin ve Özcan, 2013, s.3). Örgütün en önemli bileșeni olan insan unsuru, personel yönetiminden insan kaynağı yönetimine doğru bir geçiş yaşamıştır (Açıkalın, 2016). İnsan kaynağı örgüt performansı bağlamında oldukça önemlidir (Becker ve Gerhart, 1996; Huselid, Jackson ve Schuler, 1997). Çalışanların bireysel bağlamdaki performanslarının örgüt bağlamındaki performansa olumlu etkisi birçok deneysel çalışmaya konu olmuştur (Huselid, 1995; Guest, 1997).

Cropanzano ve Wright (2001), insan kaynağının örgüt bağlamında mutluluk ve mutsuzluk açısından incelendiğinde, mutlu çalışanların daha yüksek performans ürettiklerini belirtmektedirler. Peccei (2004) ise insan kaynağı yönetimi bağlamında mutlu bir çalışma ortamı yaratılabileceğini ifade etmektedir. Ona göre mutlu bir çalışma ortamı için de insan kaynağının mutluluğu önemlidir. Fredrickson (2001), çalışanların bireysel performanslarının olumlu duygular temelli olumlu psikolojiden etkilendiğini ortaya koymuştur. Öte yandan mutlu çalışanların daha yüksek performans ortaya koyduklarına yönelik çalışmalar oldukça fazladır (Staw, 1986; Wright ve Staw, 1999; Fogaça ve Junior, 2016). Dolayısıyla çalışanların mutluluğu örgüt bağlamında önemli olduğundan, mutlu çalışan hedefinde çalışılması gerektiği söylenebilir.

Mutlu Müşteri: Örgütsel bağlamda müş̧teri istek ve arzuları odaklı değişimlerin olduğu bir çağa şahitlik ediyoruz (Woodruff, 1997). Müşteri merkezli bir anlayışın temel alındığı bu çağda örgütler, her alanda müşteriyi ön planda tutmaktadır (Sheth, Sisodia ve Sharma, 2000). Dolayısıyla müşteri doyumu, mutluluğu konulu çalışmalar en çok çalışılan başlıklardan biri olmaktadır (Peterson ve Wilson, 1992). İşletme alanında hızla gelişen müşteriyi merkezli bu akım, kamu yönetimini de etkilemiştir. Devlet yönetimi bağlamında müşteri olarak ele alınan yurttaşların, yönetimin yeni meşruluk kaynağı olduğu söylenmektedir (Eren, 2003). Yurttaşların istek ve beklentilerini dikkate alan ve onlarla iyi diyalog kurabilen yöneticiler faaliyet ve uygulamalarını daha kolay kabul ettirmektedirler. Benzer bir gidişin görüldüğü eğitim örgütleri için de öğrencilerin müşteri olarak algılanmaları sonucu öğrenci ilgi ve isteklerine odaklanıldığı görülmektedir (Bowden, 2011). Dolayısıyla okul etkililiği bağlamında öğrenci doyumu, mutluluğu çalışmaları yapılmaya başlanmıştır (Guolla, 1999, Petruzzellis, D’Uggento 
ve Romanazzi, 2006; King ve ark., 2014). Bu ve benzeri çalışmalar müşteri mutluluğunun en temel ve sağlam ilkelerden olduğu görüşünü (Peterson ve Wilson, 1992) desteklemektedir.

\section{Sonuç}

Birey ile dünyanın kesiştiği yerde kendini bulan mutluluk, bireysel istek, amaç ve gereksinimler ile çevredekilerin dengede olduğu kalıcı bir durum olarak tanımlanmaktadır (Jacobsen, 2007). Benzer şekilde örgütler de bireyle dünya kesişiminde her alanda yer almaktadır (İllich, 2012). Öyle ki, örgütleri anlama, açıklama ve yönetme çabası dünyayı anlama çabasıyla eşdeğer görülmektedir (Baum ve Rovley, 2002). Kısaca, mutluluk ve örgüt kavramlarının bireylerin hayatlarında oldukça önemli bir yeri olduğu söylenebilir. Mutluluk, algılama olarak ne kadar pozitiflik taşıyorsa, örgüt de bir o kadar negatiflik taşımaktadır. Mutluluk ve örgüt kavramlarını kullanarak, mutlu örgüt metaforunun tartışıldığı bu çalışma zıtların uyumu olarak değerlendirilebilir. Mutluluk metaforu ile örgüt yazınında yeni bir bakış açısı sunulmaktadır. Bu bakış açısı örgüt yaşamına bir yönüyle anlaşılırlık ve yönetilebilirlik kazandırma çabası taşımaktadır. Ayrıca mutlu örgüt metaforuyla, postmodern paradigma, çok yönlü örgüt yaklaşımları ve neoklasik yönetim kuramları özellikle de Barnard'ın işbirliği kuramı somutlaştırılmaktadır.

Psotmodern paradigmanın her yerinde hissedildiği mutlu örgüt, daha yaşanabilir örgütler olarak tasarlanmıştır. Benzer şekilde Barnard'ın (1938) işbirliği kuramı mutlu örgütlerin önemli bir açıklayıcısıdır. Örgütsel hedefler gerçekleşirken (etkililik), müşteri, çalışan ve yöneticiden oluşan bireylerin ayrı ayrı mutluluğu (etkinlik) mutlu örgütün temel düşüncesidir. Bir örgütteki insan sermayesi tüm bileşenleri ile mutluluk sarmalına kazandırıldığı zaman örgütsel hedefler de gerçekleşiyorsa mutlu örgütten söz edilebilir. Mutlu örgütte müşteri, çalışan ve yönetici mutluyken aynı zamanda da hedeflere ulaşılan örgüt de mutludur.

Mutlu örgüt rasyonel, doğal ve açık örgüt kuramlarına duyarlıdır. Bunlara ek olarak şekil 1'de yer alan bütün örgüt yaklaşımlarını göz önüne alarak tasarlanmıştır. Örgütün rasyonel yanını düşünürken aynı zamanda doğal yönünü de unutmamaktadır. Bunun yanında açık örgütün görüşlerinden beslenmeyi de ihmal etmemektedir. Tüm bileşenleri ile mutluluk hedefi temel alınırken, karmaşa ve kaos yaklaşımının uyarılarına da kulak verilmektedir. Mutluluk ve işbirliği temelinde düşünce üretirken çatışmanın örgütsel yaşamın bir gereği olduğu yok sayılmamıştır. Mutlu örgüt artan teknoloji ve iletişim bağlamının bilincindedir. Bu ve bunun gibi birçok postmodern anlayış ve örgütsel gerçeklerin mutlu örgüte engeller değil katkılar üreteceği düşünülmektedir.

Uyl ve Machan'ın (1983) ifadesiyle, mutluluk araştırmaları çok geniş bir alanda ve araştırmacının düşüncesine bağlı olarak değişen sübjektif niteliktedir. Mutlu örgüt metaforunun da bu sübjektiflikten etkilenmesi olağandır. Bir örgütün mikro sosyolojik bağlamı düşünüldügüünde sübjektiflik daha da ön plana çıkmaktadır. Burada özellikle yönetici bileşeni belirleyicidir. Yöneticinin her yönüyle hayata bakışı, mutlu örgüte bakışını da etkileyecektir. Visser ve diğerleri (2013) liderin mutluluğunun, Sullivan ve 
Masters (1988) ise liderin yüz ifadesinin örgüt performansı için önemine değinmişlerdir. Mutluluk teorisinin önemli bir bileşeni olan yüz ifadesi (Davis, 1981) mutlu örgütlerin önemli bir bileşeni olan mutlu yönetici bağlamında önemlidir.

Yönetici bağlamının önemi mutlu örgüt için liderliğin önemini beraberinde getirmektedir. Liderlik mutlu örgüt için vazgeçilmezdir. Burada liderlik, yönetici kavramını kapsayan bir kavram olarak ele alınmakta (Markham ve Markham, 1995), postmodern ana akımın liderlik yönelimini desteklemektedir. Değişen liderlik kuramları ile ortaya atılan postmodern liderlik kuramları, özellikleri mutlu yöneticiler için birer araç olarak kullanılacaktır. Mutlu örgütün mutlu yöneticisi, dönüşümcü liderlikteki idealleştirilmiş etki, ilham veren motivasyon, entelektüel uyarım ve bireysel destek başlıkları ile ortak amaçları vurgularken (Burns, 1978; Bass, 1990), öz yönetim, öz farkındalık ve öz motivasyon içeren öz liderlik ile bireysel amaçları da (Manz ve Sims, 1991) önemsemelidir. Kuantum liderlikteki liderliği yeniden tanımlayan düşünce ile (Erçetin, 1999), sosyal adalet liderliğindeki kapsayıcılığg (Özdemir ve Kütküt, 2014) kendinde buluşturan mutlu yönetici, tüm bu liderlik araçlarını ve daha fazlalarını mutlu örgütler hedefinde kullanmalıdır.

Öte yandan mutlu örgüt, kalıcı mutluluğu öncelemektedir. Hemen hemen her insan veya örgüt kısa mutluluk deneyimleri yaşarken, kalıcı mutluluk ütopya olarak kalmaktadır (Jacobsen, 2007). Mutlu örgüt, örgütün kendi içinde ve çevresiyle uyumlu ve dengeli bir mutluluk sarmalı üreterek kalıcı mutluluk idealinin olabildiğince gerçekleştirilmesi tarafındadır. Şu da bir gerçektir ki, örgütler her yönüyle ve her zaman "mutlu birer aile" olamazlar. Çünkü örgüt içinde ortak değerlerin olduğu kadar birbiriyle çatışan değerlerin de olması olağandır (Hoy ve Miskel, 2012, s.15). Bir örgüt içindeki bireylerin ortaklaşa bir örgütsel değerleri olduğu gibi her birinin ayrı ayrı sahip olduğu bireysel değerler de vardır. Bireysel değerler, kişinin amaçlarına ve eylemlerine rehberlik ederken; örgütsel değerler örgütsel amaçlar ve eylemlere yön vermektedir (Vurgun ve Öztop, 2011). Sezgin (2006) okul örgütünde bireysel ve örgütsel değerlerin uyumunu incelediği çalışmasında bu konuya açıklık getirmektedir. Bireysel ve örgütsel değerlerin uyumlu olması örgütsel mutluluğa pozitif yansıyacaktır.

Sonuç olarak, örgüt bağlamında mutluluk parantezi açılan bu çalışmada mutlu örgüt metaforu tartışılmıştır. Bu çalışmada temel kaygı örgüt yaşamını daha yaşanabilir kılabilmektir. Bireyle dünyanın kesişiminde bulunan mutluluk ve örgüt olguları daha yaşanabilir bir dünya için birleştirilmiştir. Bu birleşmenin ürünü olan mutlu örgüt, mutlu bireyler (yönetici, çalışan, müşteri) ile ulaşılmış örgütsel hedefler bağlamında konumlandırılmıştır. Bu konum, mutluluk ve örgüt yazını ile desteklenmiştir. Çalışma sonunda şu öneriler verilebilir:

Mutluluk kavramı öznel olduğu için, her örgüt bağlamında bir anlam birliği sağlanmalıdır.

$\checkmark$ Örgütler bağlamında mutluluk kavramı ele alınırken uzun süreli mutluluk anlayışı temel alınmalidır. 
Müşteri, çalışan ve yönetici olmak üzere her bireyin mutluluk pratikleri geliştirilmelidir.

$\checkmark$ Özellikle yöneticilere mutluluk ve mutlu olma eğitimleri verilmelidir.

$\checkmark$ Liderlik mutlu örgütler için önemle ele alınmalıdır.

$\checkmark$ Mutlu örgüt hedefinde örgütsel amaçlar göz ardı edilmemelidir.

$\checkmark$ Mutlu örgütün bileşenlerini hep birlikte ele alan çalışmalar çoğaltılabilir.

$\checkmark$ Sadece müşteri, sadece çalışan ve sadece yönetici mutluluğu ile mutlu örgüt idealine ulaşılamayacağı unutulmamalıdır.

$\checkmark$ Mutluluk, bireysel ve çevresel istekler, hedefler arasında bir denge ürünü olduğu için, bireyler kendilerine uygun örgütlerde çalışmalıdır.

$\checkmark$ Mesleki rehberlik yapılırken bireyin değerleri ile çalışacağı örgütün değerlerinin uyumu önemsenmelidir.

$\checkmark$ Bu haliyle teorik olan mutlu örgüt, uygulamalı olarak çeşitli örgütlerde sınanmalıdır.

Mutlu örgüt, örgütsel bağlamda farklı konularla ilişkisel çalışmalara konu edilerek geliştirilebilir.

\section{Kaynaklar}

Açıkalın, A. (2016). Çağdaş örgütlerde insan kaynă̆ının yönetimi. Ankara: Pegem Akademi

Barnard, Ç. I. (1938). The function of executive. Massachusetts: Harvard University Press

Bass, B. M. (1990). Bass Stogdill's handbook of leadership: theory, research, and managerial applications. 3rd ed. New York: Free Press.

Baum, J. A., ve Rowley, T. J. (2002). Companion to organizations: An introduction. The Blackwell companion to organizations 1-34.

Becker, B. ve Gerhart, B. (1996). "The impact of human resource management on organizational performance: progress and prospects” . The Academy of Management Journal 39(4): 779-801.

Bell, L. A. (1980). "The school as an organisation: A re-appraisal”. British Journal of Sociology of Education 1(2): 183-192.

Benditt, T. (1974). "Happiness”. Philosophical Studies: An International Journal for Philosophy in the Analytic Tradition 25(1): 1-20.

Bowden, L. J. (2011). “Engaging the student as a customer: a relationship marketing approach”. Marketing Education Review 21(3): 211-228.

Bryman, A. E. (1992). Charisma and leadership in organizations. London: Sage.

Burns, J. M. (1978). Leadership, New York: Harper \& Row Publishers.

Bursalığlu, Z. (2010). Okul yönetiminde yeni yapı ve davranış. Ankara: Pegem A Yayıncilik 
Bursalıŏlu, Z. (2012). Eğitim yönetiminde teori ve uygulama. Ankara: Pegem Akademi Cropanzano, R. ve Wright, T. A. (2001). "When a "happy" worker is really a "productive" worker: A review and further refinement of the happy-productive worker thesis”. Consulting Psychology Journal: Practice and Research 53(3):182-199.

Davis, W. (1981). “A theory of happiness”. American Philosophical Quarterly 18(2): 111-120.

DeCenzo, D.A. ve Robbins, S.P. (2005). Fundamentals of human resource management. Eight edition. John Wiley and Sons

Diener, E. ve Diener, C. (1996). "Most people are happy”. Psychological Science (7)3: 181-185.

Diener, E. ve Seligman, M. E. P. (2002). “Very happy people”. Psychological Science 13(1): 81-86.

Döş, İ. (2013). “Mutlu okul”. Eğitim ve Bilim 38(170): 265-280.

Drucker, P. F. (1999). Management. Revised Edition. California: The Drucker Institute.

Drucker, P. F. (2011). Büyük değişimler çağında yönetim. Çev. Z. Dicleli. İstanbul: Optimist Yayınları.

Erçetin, Ş. Ş. (1999). "Kuantum liderlik paradigması ile eğitim liderliğinin açımlanması". Cumhuriyet Döneminde Ĕ̌itim. Talim ve Terbiye Dairesi Ankara: M.E.B. Yayınları.

Eren, V. (2003). "Kamu yönetiminde meşruluk temeli olarak müşteri odaklı yönetim yaklaşımı". Ankara Üniversitesi SBF Dergisi 58(1): 55-71.

Eroğlu, E. (2005). "Müşteri memnuniyeti ölçüm modeli”. I. Ü. İşletme Fakültesi Işsletme Dergisi (34)1: 7-25.

Fogaça, N. ve Junior, F. A. C. (2016). "Is "happy worker" more productive". Management Studies 4(4): 149-160.

Fornell, C. (1992). "A national customer satisfaction barometer: the Swedish experience”. Journal of Marketing (56)1: 6-21.

Fredrickson, B. L. (2001). "The role of positive emotions in positive psychology". American Psychologist 56(3): 218-226.

Goldstein, I. (1980). “Why people prefer pleasure to pain”. Philosophy 55(213): 349362.

Griffin, J. (2007). “What do happiness studies study?”. Journal of Happiness Studies 8:139-148.

Guest, D. E. (1997). "Human resource management and performance: a review and research agenda”. The International Journal of Human Resource Management 8(3): 263-276.

Guolla, M. (1999) “Assessing the teaching quality to student satisfaction relationship: applied customer satisfaction research in the classroom”. Journal of Marketing Theory and Practice 7(3): 87-97.

Haybron, D. M. (2001). "Happiness and pleasure”. Philosophy and Phenomenological Research (62)3: 501-528. 
Haybron, D. M. (2003). "What do we want from a theory of happiness?" Metaphilosophy 34(3): 305-329.

Haybron, D. M. (2005). “On being happy or unhappy”. Philosophy and Phenomenological Research LXXI(2): 287-318.

Haybron, D. M. (2007). "Do we know how happy we are? On some limits of affective introspection and recall". Nous 41(3): 394-428.

Heck, R.H. ve Hallinger, P. (2009). "Assessing the contribution of distributed leadership to school improvement and growth in math achievement". American Educational Research Journal 46(3): 659-689.

Hoy, W. K. ve Miskel, C. G. (2012). Educational administration theory, research and practice. Çev. Ed. Selahattin Turan. Ankara: Nobel Yayınları

Huselid, M. A. (1995). "The impact of human resource management practices on turnover, productivity, and corporate financial performance". The Academy of Management Journal 38(3): 635-672.

Huselid, M. A., Jackson, S. E. ve Schuler, R. S. (1997). “Technical and strategic human resource management effectiveness as determinants of firm performance". The Academy of Management Journal 40(1): 171-188.

İllich, I. (2012). Okulsuz toplum. Çev: M. Özay. İstanbul: Şule Yayınları.

Jacobsen, B. (2007). "What is happiness? The concept of happiness in existential psychology and therapy”. Existential Analysis 18(1): 39-53.

Jin, S., Seo, M. ve Shapiro, D. L. (2016). "Do happy leaders lead better? Affective and attitudinal antecedents of transformational leadership”, The Leadership Quarterly 27: 64-84.

Kaiser, R. B., Hogan, R. ve Craig, S. B. (2008). "Leadership and the fate of organizations”. American Psychologist 63(2): 96-110.

King, K. A., Vidourek, R. A., Merianos, A. L. ve Singh, M. (2014). “A study of stress, social support, and perceived happiness among college students". The Journal of Happiness \& Well-Being 2(2): 132-144.

Lakoff, G. ve Johnson, M. (1980). Metaphors we live by. Chicago: The University of Chicago Press

Langton, N. ve Robbins, S.P. (2004). Fundamentals of organizational behavior. Third Canadian Edition

Leonardi, P.M. ve Barley, W.C. (2011) "Materiality as organizational communication: technology, intent, and delegation in the production of meaning”. T. Kuhn (Ed.). Matters of communication: political, cultural, and technological challenges to communication theorizing, (101-122). Cresskill, NJ: Hampton Press.

Manz, C. C. ve Sims, H. P. (1991). "Superleadership: Beyond the myth of heroic leadership”. Organizational Dynamics 19: 18-35.

Markham, S. E. ve Markham, İ. S. (1995). "Self managementand self leadershipreexamined: A levels of analysisperspective”. Leadership Quarterly 6(3): 343-359.

McMahon, D. M. (2005). “The quest for happiness”. The Wilson Quarterly 29(1): 6271. 
Morgan, G. (1998). Yönetim ve örgüt teorilerinde metafor. Çev: G. Bulut. İstanbul: MESS Yayınları

Noddings, N. (2006). Ĕgitim ve mutluluk. Çev: Zuhal Bilgin. İstanbul: Kitap Yayınevi

Nussbaum, M. C. (2008). "Who is the happy warrior? philosophy poses questions to psychology”. The Journal of Legal Studies 37(2): 81-113.

Oishi, S., Graham, J., Kesebir, S. ve Galinha, I. C. (2013). "Concepts of Happiness Across Time and Cultures”. Personality and Social Psychology Bulletin 39(5): 559577.

Özdemir, M. ve Kalayc1, H. (2013). “Okul bağlılığ1 ve metaforik okul algısı üzerine bir inceleme: Çankırı ili örneği”. Kuram ve Uygulamada Eğitim Bilimleri 13(4): 21252137.

Özdemir, M. (2012). "Lise öğrencilerinin metaforik okul algılarının çeşitli değişkenler bakımından incelenmesi”. Eğitim ve Bilim 37(163): 96-109.

Özdemir, M. (2014). Eğitim örgütlerinde insan kaynaklarl yönetimi. Ankara: Anı Yayınc1lik

Özdemir, M. ve Kütküt, B. (2015). “Sosyal adalet liderliği ölçeği’nin (salö) geliştirilmesi: geçerlik ve güvenirlik çalışması”. Ahi Evran Üniversitesi Kırşehir Eğitim Fakültesi Dergisi 16(3): 201-218.

Peccei, R. (2004). Human resource management and the search for the happy workplace. Erasmus Research Institute of Management (ERIM). (http://hdl.handle.net/1765/1, 14 Temmuz 2016' da erişildi)

Peterson, R. A. ve Wilson, W. R. (1992). "Measuring customer satisfaction: fact and artifact”. Journal of the Academy of Marketing Science 20 (1): 61-71.

Petruzzellis, L., D’Uggento, A. M. ve Romanazzi, S. (2006). "Student satisfaction and quality of service in Italian universities”. Managing Service Quality 16(4): 349-364.

Popper, K. R. (2005). Bilimsel araştırmanın mantığ . Çev. İ. Aka ve İ. Turan. İstanbul: Yap1 Kredi Yayınları

Pugh, D. S. ve Hickson, D. J. (2016). Great writers on organizations: the third omnibus edition. NY: Routledge

Quick, J. C. ve Quick, J. D. (2004). "Healthy, happy, productive work: a leadership challenge”. Organizational Dynamics (33)4: 329-337.

Robbins, S. P. ve Coulter, M. (2012) Management. Eleventh Edition. Pearson Education Ryan, R. M. ve Deci, E. L. (2001). "On happiness and human potentials: A review of research on hedonic and eudaimonic well-being”. Annu. Rev. Psychology 52: 141-166.

Scott, A. (1997). “Modernity's machine metaphor”. The British Journal of Sociology 48(4): 561-575.

Scott, W. R. ve Davis, G. F. (2007). Organizations and organizing: rational, natural, and open system perspectives. Pearson Prentice Hall

Selznick, P. (1948). "Foundations of the theory of organization”. American Sociological Review 13(1): 25-35. 
Sheth, J. N., Sisodia, R. S. ve Sharma, A. (2000). "The antecedents and consequences of customer-centric marketing”. Journal of the Academy of Marketing Science, 28(1): 5566.

Staw, B. M. (1986). "Organizational psychology and the pursuit of the happy/productive worker”. California Management Review (28)4: 40-54.

Sullivan, D. G. ve Masters, R. D. (1988). ““"Happy warriors": Leaders' facial displays, viewers' emotions, and political support”. American Journal of Political Science (32)2: 345-368.

Şişman, M. (1996). "Postmodernızm tartışmaları ve örgüt kuramındaki yansımaları". Eğitim Yönetimi 2(3): 451-464.

Thomas, D. A. L. (1968). “Happiness”. The Philosophical Quarterly 18(71): 97-113.

Tsoukas, H. (1991). “A transformational view of metaphors in organizational science”. Academy of Management Review 16(3): 566-585.

Türk Dil Kurumu (TDK) Sözlüğü (http://www.tdk.gov.tr/ 9 Temmuz 2016'da erişildi)

Uyl, D. D. ve Machan, T. R. (1983). "Recent work on the concept of happiness". American Philosophical Quarterly 20(2): 115-134.

Veenhoven, R. (2005). "Is life getting better? How long and happy people live in modern society". European Psychologist special section on 'Human development and Well-being' 10: 330-343.

Visser, V. A., Knippenberg, D. V., Kleef, G. A. V. ve Wisse, B. (2013). "How leader displays of happiness and sadness influence follower performance: Emotional contagion and creative versus analytical performance”. The Leadership Quarterly 24; 172-188.

Waterman, A. S. (1993). "Two conceptions of happiness: contrasts of personal expressiveness (eudaimonia) and hedonic enjoyment”. Journal of Personality and Social Psychology (64)4: 678-691.

White, N. (2006). A brief history of happiness. Blackwell Publishing Ltd. (http://samples.sainsburysebooks.co.uk/9781405153126_sample_387982.pdf, $\quad 14$ Temmuz 2016' da erişildi)

Wilson, J. (1968). “Happiness”. Analysis 29(1): 13-21.

Woodruff, R. B. (1997). "Customer value: The next source for competitive advantage". Journal of the Academy of Marketing Science 25(2): 139-153.

Wright, T. A. ve Staw, B. M. (1999). "Further thoughts on the happy-productive worker”. Journal of Organizational Behavior 20: 31-34.

Yukl, G. (2010). Leadership in organizations. Seventh Edition. New Jersey: Pearson Education

Zelenski, J. M., Murphy, S. A ve Jenkins, D. A. (2008). “The happy-productive worker thesis revisited”. Journal Happiness Studies 9: 521-537. 